\title{
Age is not the only risk factor in COVID-19: the role of comorbidities and of long staying in residential care homes
}

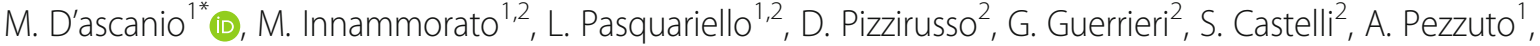 \\ C. De vitis ${ }^{2}$, P. Anibaldi ${ }^{3}$, A. Marcolongo ${ }^{4}$, R. Mancini ${ }^{2}$, A. Ricci ${ }^{2}$ and S. Sciacchitano ${ }^{2,5}$
}

\begin{abstract}
Background: The actual SARS-CoV-2 outbreak caused a highly transmissible disease with a tremendous impact on elderly people. So far, few studies focused on very elderly patients (over 80 years old). In this study we examined the clinical presentation and the outcome of the disease in this group of patients, admitted to our Hospital in Rome.

Methods: This is a single-center, retrospective study performed in the Sant'Andrea University Hospital of Rome. We included patients older than 65 years of age with a diagnosis of COVID-19, from March 2020 to May 2020, divided in two groups according to their age (Elderly: 65-80 years old; Very Elderly $>80$ years old). Data extracted from the each patient record included age, sex, comorbidities, symptoms at onset, the Pneumonia Severity Index (PSI), the ratio of the partial pressure of oxygen in arterial blood ( $\mathrm{PaO} 2)$ to the inspired oxygen fraction (FiO2) (P/F) on admission, laboratory tests, radiological findings on computer tomography (CT), length of hospital stay (LOS), mortality rate and the viral shedding.

The differences between the two groups were analyzed by the Fisher's exact test or the Wilcoxon signed-rank test for categorical variables and the Mann-Whitney $U$ test for continuous variables. To assess significance among multiple groups of factors, we used the Bonferroni correction.

The survival time was estimated by Kaplan-Meier method and Log Rank Test. Univariate and Multivariate logistic regression were performed to estimate associations between age, comorbidities, provenance from long-stay residential care homes (LSRCH) s and clinical outcomes.
\end{abstract}

Results: We found that Very Elderly patients had an increased mortality rate, also due to the frequent occurrence of multiple comorbidities. Moreover, we found that patients coming from LSRCHs appeared to be highly susceptible and vulnerable to develop severe manifestations of the disease.

Conclusion: We demonstrate that there were considerable differences between Elderly and Very Elderly patients in terms of inflammatory activity, severity of disease, adverse clinical outcomes. To establish a correct risk stratification, comorbidities and information about provenience from LSRCHs should be considered.

Keywords: Elderly, Comorbidities, COVID 19, Residential care homes

* Correspondence: dascaniomichela87@gmail.com

'Division of Pneumology, Sant'Andrea Hospital, Via di Grottarossa, 1035-1039,

00189 Rome, Italy

Full list of author information is available at the end of the article

(c) The Author(s). 2021 Open Access This article is licensed under a Creative Commons Attribution 4.0 International License, which permits use, sharing, adaptation, distribution and reproduction in any medium or format, as long as you give appropriate credit to the original author(s) and the source, provide a link to the Creative Commons licence, and indicate if changes were made. The images or other third party material in this article are included in the article's Creative Commons licence, unless indicated otherwise in a credit line to the material. If material is not included in the article's Creative Commons licence and your intended use is not permitted by statutory regulation or exceeds the permitted use, you will need to obtain permission directly from the copyright holder. To view a copy of this licence, visit http://creativecommons.org/licenses/by/4.0/. The Creative Commons Public Domain Dedication waiver (http://creativecommons.org/publicdomain/zero/1.0/) applies to the data made available in this article, unless otherwise stated in a credit line to the data. 


\section{Background}

The COVID 19 outbreak represents an historically unprecedented pandemic, particularly dangerous and potentially lethal for elderly population. Since the beginning of the actual SARS-CoV-2 outbreak it was evident that older people, compared to younger ones, were at higher risk to get the infection and to develop a more severe disease with unfavorable prognosis. In Italy, the National Healthcare Service, registered 418,142 total cases of COVID-19 and 39,412 deaths, as of November 3, 2020 [1]. The mean age of patients that died was 80 years, at least 20 years higher than that registered in infected people. The majority of those who are infected, that have a self-limiting infection and do recover are, in fact, younger. Conversely, those that suffer a more severe disease, that require intensive care unit admission and eventually pass away are older [2, 3].

Many reports indicate that elderly patients with COVID-19 are more likely to progress to severe disease compared to young and middle-aged ones [2]. These observations have a particular and relevant negative impact in Europe. Of the top 30 countries with the largest percentage of older people, all but one (Japan) are States in Europe and Italy is considered "a country of old people" because the life expectancy is over 80 years of age [4]. The situation is critical in the long-stay residential care homes (LSRCHs), where many elderly people and people with disabilities and severe cardiovascular and neurological diseases live all together in close contact, facilitating the dynamics of virus transmission. Residents in LSRCHs are a vulnerable population group and it has been reported that the proportion of COVID-19 cases who have died in these LSRCHs has exceeded $60 \%$ of all reported deaths [5].

In a recent report by the Organization for Economic Cooperation and Development (OECD) [6] over 75,000 deaths have been registered across 13 European countries amongst residents in long term care institutions (as of early October 2020), accounting for almost half of the total deaths caused by COVID-19. In Italy there are more than 3000 of such facilities, with 186,872 beds. That is why the Istituto Superiore di Sanità (ISS) launched a National survey on COVID-19 infection in LSRCHs, to monitor the situation and to solicit special strategies against spreading of infection [7]. The results of this Survey have been described in a final report posted on May 5th 2020 [8]. The data obtained from a total of 3292 LSRCHs in different Italian regions indicated that the mortality rate of patients, with proved infection plus those with symptoms that suggested positivity, was equal to $3.1 \%$, but, in some regions, it reached the value of $6.5 \%$. The main problems reported by the personnel in facing the pandemic were related to the difficulties in isolating the positive patients and in transfer the critical ones to the hospital. In addition, they complained about the scarcity of tests, adequate information and personal protective equipment.

However, despite the huge amount of data on COVID-19 worldwide, the reasons why older people are at significantly increased risk of severe disease following infection from COVID-19 are not clear. Age could not be the only risk for severe disease. It has been reported that people in their teens or twenties may develop a severe form of the disease, may require intensive care and may die as well [9]. On the other side, people who age healthily seems to be less at risk. Besides the physiological changes associated with ageing, other factors could be involved, including the decreased immune function and the occurrence of multimorbidity [10].

To date there is little information on COVID-19 in patients over 80 years of age. Therefore, in this study, we focused our attention on very elderly population ( $>80$ years of age) [11, 12] that referred to our University Hospital during the actual SARS-CoV-2 outbreak and we have analyzed the differences between elderly people and very elderly ones. Our aim was to try to figure out the reason why elderly and very elderly people are more prone to be infected and to develop a more severe form of the disease. We considered clinical aspects, presence of comorbidities, laboratory and radiological findings as well as their outcome, including the length of stay, mortality and viral shedding in nasal/oropharyngeal swabs.

\section{Methods}

\section{Study design and participants}

This is a single-center, retrospective study performed in the Sant'Andrea University Hospital of Rome. We included patients older than 65 years of age with a diagnosis of COVID-19 from March 2020 to May 2020. The diagnosis was based on the Chinese Clinical Guidance For COVID-19 Pneumonia Diagnosis and Treatment published and updated by the National Health Commission of China (NHFPC, 2020). All the COVID-19 patients had either positive real-time reverse transcription polymerase chain reaction (rRT-PCR) from respiratory samples [13] or positive serological test of specific IgM antibody to SARS-CoV-2. Eighty-one patients were divided into two groups according to their age. Forty-one patients with ages ranging from 65 to 79 years were included in Elderly Group, the remaining forty patients with ages $\geq 80$ years were included in group named Very Elderly.

Data extracted from the each patient record included age, sex, comorbidities, symptoms at onset, the Pneumonia Severity Index (PSI), the ratio of the partial pressure of oxygen in arterial blood ( $\mathrm{PaO} 2)$ to the inspired oxygen fraction ( $\mathrm{FiO} 2)(\mathrm{P} / \mathrm{F})$ on admission, laboratory tests, radiological findings on computer tomography (CT), 
length of hospital stay (LOS), mortality rate and the viral shedding.

\section{Serum markers of inflammation and sepsis}

We analyzed several different serum markers of systemic inflammation and sepsis, including the neutrophil to lymphocyte ratio (NLR), the Platelets to Lymphocytes Ratio (PLR), the pro-calcitonin (PCT) and the highsensitive C-Reactive Protein (hs-CRP).

\section{Radiological evaluation and analysis}

Chest CT were obtained on a 128-slice scanner (GE Revolution EVO CT Scanner, GE Medical Systems, Milwaukee, WI, USA), with patients in supine position and during end-inspiration, without iodinated contrast medium injection. The following technical parameters were used: tube voltage: $120 \mathrm{kV}$; tube current modulation: 100-250 mAs; spiral pitch factor: 0.98; collimation width: 0.625. Images were reconstructed with a sharp convolution kernel (BONEPLUS) at a slice thickness of $1.25 \mathrm{~mm}$.

DICOM data have been transferred onto a PACS workstation (Centricity Universal Viewer v.6.0, GE Medical Systems, Milwaukee, WI, USA) and independently evaluated by two expert radiologists, using a dedicated software (Thoracic VCAR v13.1, GE). Only imaging features related to COVID-19, according to the most recent literature $[14,15]$ have been considered valid for image analysis.

\section{Outcomes}

Length of stay and death were both analyzed.

During hospitalization, an RT-PCR assay was conducted every other day after the remission of clinical symptoms or radiography of patients, and the corresponding date was recorded. The duration of viral shedding was defined as the number of days from the onset of the symptoms until the successive negative detection of SARS-CoV-2 RNA, which was consistent with other studies of COVID-19 [16, 17].

\section{Statistical analysis}

Continuous variables were summarized as either means and standard deviations. Categorical variables were described as frequencies and percentages. The differences between the two groups were analyzed by the Fisher's exact test or the Wilcoxon signed-rank test for categorical variables and the Mann-Whitney $U$ test for continuous variables. We performed pairwise comparisons with a Bonferroni correction for multiple comparisons. The statistical adjusted significance was accepted at the adjusted $p$ value $<0.0008$.

The survival time was estimated by Kaplan-Meier method and Log Rank Test. Univariable Cox proportional hazard regression was performed to estimate associations between age, comorbidities and provenance from LSRCHs and clinical outcomes of mortality. Hazard ratios (HR), odds ratio (OR) and 95\% confidence intervals (CI) were reported. A $p<0.05$ was considered statistically significant. Age, comorbidities and provenance from residential care homes were used as predictors in a multivariable logistic regression model, with a binary outcome (mortality). Two model were created (Model 1: all of them; Model 2: only age). Calibration of agreement between the predicted and observed probabilities was assessed using the HosmerLemeshow goodness-of-fit test, indicating a poor fit for $p<0.05$.

All analyses were performed using the GraphPad Prism software (version 8.4.1) (GraphPad Software, San Diego, CA).

\section{Ethical approval}

A written informed consent was obtained by participant to the study. The study was approved by our Institutional Ethical Committee (Sapienza University of Rome, Italy) (Prot.\# 52SA_2020, RIF. CE 5773_2020), on the basis that it complied with the declaration of Helsinki and that the protocol followed existing good clinical practice guidelines.

\section{Results}

\section{Clinical characteristics}

A total of 81 consecutive patients, referred to our hospital for COVID-19 and identified as laboratoryconfirmed SARS-CoV-2 infection, have been included in the study. They were 37 men and 44 women. Their median age is 79.7 years (ranging from 65 to 94 years). Demographic and clinical characteristics are listed in Table 1. On admission, most patients had shortness of breath (61\%). There were differences in cough and fever between two groups. Both the respiratory scores (P/F and PSI) were higher in Very Elderly patients.

Among comorbidities, the more representative were neurological and cardiovascular diseases. The incidence of both were more in Very Elderly patients.

\section{Laboratory results}

All data obtained from Laboratory results are resumed in Table 2.

All of our COVID-19 patients, showed normal values of red blood cells (RBC), white blood cell (WBC) and platelets (PLT), measured on admission. Among the different serum markers of systemic inflammation and sepsis measured, we observed a higher value of the NLR and hs-CRP in Very Elderly compared to Elderly. 
Table 1 Demographic and Clinical Characteristics

\begin{tabular}{|c|c|c|c|c|}
\hline & $\begin{array}{l}\text { Total } \\
(n=81)\end{array}$ & $\begin{array}{l}\text { Age } 65-79 \\
(n=41)\end{array}$ & $\begin{array}{l}\text { Age } \geq 80 \\
(n=40)\end{array}$ & $p$ value \\
\hline Age (years) & $79.69 \pm 8.01$ & $73.05 \pm 4.71$ & $86.5 \pm 3.89$ & NS \\
\hline Male (n, \%) & $37(46 \%)$ & $22(53 \%)$ & $15(37 \%)$ & NS \\
\hline \multicolumn{5}{|l|}{ Symptoms } \\
\hline Cough & $29(35 \%)$ & $20(49 \%)$ & $9(22 \%)$ & 0.01 \\
\hline Dyspnea & $50(61 \%)$ & $24(58 \%)$ & $26(65 \%)$ & NS \\
\hline Fever & $37(45 \%)$ & $25(61 \%)$ & $12(30 \%)$ & 0.005 \\
\hline \multicolumn{5}{|l|}{ Respiratory Score } \\
\hline $\mathrm{P} / \mathrm{F}$ & $280.37 \pm 113.64$ & $316.58 \pm 105.38$ & $241.66 \pm 110.95$ & 0.009 \\
\hline PSI & $121.59 \pm 32.51$ & $109.2 \pm 27.62$ & $134.3 \pm 32.52$ & 0.0003 \\
\hline \multicolumn{5}{|l|}{ Medical history (n, \%) } \\
\hline Neurological disease & $42(52 \%)$ & $17(40 \%)$ & 25 (59\%) & 0.005 \\
\hline Cardiovascular disease & $56(69 \%)$ & $23(56 \%)$ & $33(82 \%)$ & 0.01 \\
\hline Diabetes & $22(27 \%)$ & $10(24 \%)$ & $12(30 \%)$ & NS \\
\hline Respiratory disease & $28(34 \%)$ & $15(36 \%)$ & $13(33 \%)$ & NS \\
\hline Cancer disease & $20(25 \%)$ & $12(29 \%)$ & $8(20 \%)$ & NS \\
\hline Chronic Kidney disease & $16(19 \%)$ & $7(17 \%)$ & $9(22 \%)$ & NS \\
\hline
\end{tabular}

Was used Bonferroni correction for multiple comparisons. The statistical adjusted significance was accepted at the adjusted $p$ value $<0.0008$

Abbreviations: P/F partial pressure of oxygen/inhalation volumetric fraction of molecular oxygen, $P S /$ pneumonia severity index

\section{Radiological findings}

Results of the radiological evaluation of our elderly patients are reported in Table 3. On admission, the abnormalities in chest CT images detected in COVID-19 patients consisted in acute lung inflammatory lesions, involving one or multiple lobes. The proportion of bilateral and multiple lobes involvement is high in both groups and no difference was found. Most of the patients presented on CT scan ground glass opacity (82\%), whereas pleural effusion has been found in $38.3 \%$ of them and difference between the two groups was significant.

\section{Outcomes}

The duration of hospitalizations (LOS), measured in days, was longer for Very Elderly compared with Elderly but the difference is not statistically significant.

The median duration of viral shedding in the current study was 22 days. Based on the median as the cut-off point, the prolonged period of viral shedding was defined as a duration of more than 21 days. Among Very Elderly, 31 patients were still positive after 21 days respect 23 patients of Elderly patients $(p<0.05)$.

The Kaplan-Meier method was used to estimate the proportion of patients into two groups with a positive detection of SARS-CoV-2 RNA after 30 days from the onset of the symptoms (Fig.1). Very elderly patients showed a longer viral shedding compared to elderly one (HR 2.86; 95\% CI 0.69-11.81; $p$ value $=0.03$ ).
By the end of May 19 patients (23\%) died. Most of them belonged to the Very Elderly group. The mortality rate was significantly higher in Very Elderly (37.5\%) than in Elderly (9.8\%). Kaplan-Meier is shown in Fig. 2 (HR 4.5 ; 95\% CI 1.8-11.14; $p$ value $=0.003$ )

To explore the risk factors of death, univariate and multivariate logistics regression was conducted. Independently of age there are other factors that influence the outcome of COVID-19 patients. In particular, the presence and the number of comorbidities is a critical factor in predicting death in both elderly and very elderly patients. Another factor is the type of emergency admission to the hospital. A higher mortality rate was registered in patients admitted to the hospital from LSRCHs nearby Rome compared to those coming from their home and admitted directly via a general practitioner.

Table 4 reported the univariate logistic regression model suggesting that age (OR, 1.109; 95\% CI: 1.031 to 1.206; $p=0.004)$, comorbidities (OR, $1.69 ; 95 \% \mathrm{CI}: 1.124$ to $2.652 ; p=0.01$ ) and provenience from LSRCHs (OR, 3.29; $95 \%$ CI: 1.057 to $12.58 ; p=0.03$ ) were a risk factors for death.

Table 5 showed the multivariate logistic regression analysis. It was found that the model with age, comorbidities and data regarding provenience from LSRCHs was preferred compared to the model that considered only age in predicting mortality (Hosmer and Lemeshow goodness-of-fit test, $p=0.79$ ). 
Table 2 Laboratory Results

\begin{tabular}{|c|c|c|c|c|}
\hline & $\begin{array}{l}\text { Total } \\
(n=81)\end{array}$ & $\begin{array}{l}\text { Age } 65-79 \\
(n=41)\end{array}$ & $\begin{array}{l}\text { Age } \geq 80 \\
(n=40)\end{array}$ & $p$ value \\
\hline \multicolumn{5}{|c|}{ Hemocromocytometric parameters } \\
\hline Haemoglobin (g/dl) & $12.23 \pm 1.81$ & $12.57 \pm 1.98$ & $11.89 \pm 1.56$ & NS \\
\hline Platelet (10^3/uL) & $211.07 \pm 101.7$ & $204.63 \pm 99.4$ & $217.33 \pm 104.91$ & NS \\
\hline WBC $(10 \wedge 3 / u L)$ & $8.37 \pm 4.13$ & $8.08 \pm 4.82$ & $8.66 \pm 3.34$ & NS \\
\hline Neutrophil \% & $74.1 \pm 13.61$ & $70.86 \pm 14.97$ & $77.33 \pm 11.38$ & 0.03 \\
\hline Lymphocytes \% & $18.07 \pm 11.85$ & $20.9 \pm 13.41$ & $15.23 \pm 9.39$ & 0.03 \\
\hline Monocytes \% & $6.72 \pm 3.35$ & $7.04 \pm 3.05$ & $6.39 \pm 3.61$ & NS \\
\hline Eosinophil \% & $0.85 \pm 1.08$ & $0.82 \pm 1.04$ & $0.88 \pm 1.14$ & NS \\
\hline Basophil \% & $0.27 \pm 0.34$ & $0.31 \pm 0.41$ & $0.23 \pm 0.25$ & NS \\
\hline Neutrophil $\left(\mathrm{M} / \mathrm{mm}^{\wedge} \wedge\right)$ & $6.34 \pm 3.36$ & $5.86 \pm 3.54$ & $6.82 \pm 3.14$ & NS \\
\hline Lymphocytes $(\mathrm{M} / \mathrm{mm} \wedge 3)$ & $1.44 \pm 1.71$ & $1.67 \pm 2.28$ & $1.21 \pm 0.76$ & NS \\
\hline Monocytes $(\mathrm{M} / \mathrm{mm} \wedge 3)$ & $0.55 \pm 0.37$ & $0.55 \pm 0.38$ & $0.54 \pm 0.35$ & NS \\
\hline Eosinophil $(\mathrm{M} / \mathrm{mm} \wedge 3)$ & $0.41 \pm 3.01$ & $0.76 \pm 4.26$ & $0.07 \pm 0.1$ & NS \\
\hline Basophil $\left(\mathrm{M} / \mathrm{mm}^{\wedge} \wedge 3\right)$ & $0.03 \pm 0.08$ & $0.03 \pm 0.07$ & $0.04 \pm 0.09$ & NS \\
\hline \multicolumn{5}{|l|}{ Hormone Levels } \\
\hline $\mathrm{FT} 4$ (ng/dl) & $1.1 \pm 0.23$ & $1.2 \pm 0.27$ & $1.03 \pm 0.18$ & 0.04 \\
\hline FT3 $(p g / m l)$ & $1.78 \pm 0.55$ & $1.81 \pm 0.55$ & $1.76 \pm 0.57$ & NS \\
\hline $\mathrm{TSH}(\mathrm{uU} / \mathrm{ml})$ & $1.01 \pm 0.85$ & $0.87 \pm 0.81$ & $1.11 \pm 0.87$ & NS \\
\hline Vitamin D 25-OH (ng/ml) & $10.66 \pm 9.57$ & $8.4 \pm 9.11$ & $11.92 \pm 9.84$ & NS \\
\hline Ferritin (ng/ml) & $843.4 \pm 1110.26$ & $692.15 \pm 932.01$ & $1006.76 \pm 1274.7$ & NS \\
\hline \multicolumn{5}{|c|}{ Serum Markers of inflammation } \\
\hline Procalcitonin (ng/ml) & $1.21 \pm 3.92$ & $0.53 \pm 1.01$ & $1.76 \pm 5.15$ & NS \\
\hline NLR & $6.71 \pm 5,44$ & $5.35 \pm 3.79$ & $8.06 \pm 6.47$ & 0.02 \\
\hline PLR & $206.76 \pm 123.88$ & $188.66 \pm 101.18$ & $223.89 \pm 141.35$ & NS \\
\hline C-Reactive Protein (mg/dl) & $7.54 \pm 7.28$ & $5.53 \pm 6.23$ & $9.55 \pm 7.76$ & 0.02 \\
\hline \multicolumn{5}{|l|}{ Blood Biochemistry } \\
\hline Creatinine (mg/dl) & $1.23 \pm 0.98$ & $1.11 \pm 0.63$ & $1.35 \pm 1.23$ & NS \\
\hline Urea (mg/dl) & $29.96 \pm 25.22$ & $26.33 \pm 22.99$ & $33.6 \pm 27.07$ & NS \\
\hline AST (U/L) & $32.7 \pm 36.23$ & $31.35 \pm 17.38$ & $34.08 \pm 48.79$ & NS \\
\hline $\mathrm{ALT}(\mathrm{U} / \mathrm{L})$ & $25.09 \pm 31.55$ & $27.5 \pm 21.21$ & $22.62 \pm 39.62$ & NS \\
\hline $\mathrm{LDH}(\mathrm{U} / \mathrm{L})$ & $312.89 \pm 134.51$ & $294.41 \pm 126.18$ & $333 \pm 142.16$ & NS \\
\hline Alkaline phoshatase $(U / L)$ & $95.33 \pm 50.86$ & $92.48 \pm 54.72$ & $98.17 \pm 47.74$ & NS \\
\hline Troponin (pg/ml) & $48.26 \pm 81.84$ & $36.48 \pm 53.46$ & $60.05 \pm 102.46$ & NS \\
\hline D-dimer (ng/ml) & $974.93 \pm 1270.89$ & $861.18 \pm 1270.87$ & $1091.76 \pm 1277.66$ & NS \\
\hline \multicolumn{5}{|l|}{ Serum Immunological Markers } \\
\hline T cells (\%) & $74.06 \pm 11.43$ & $76.31 \pm 7.91$ & $72.06 \pm 13.77$ & NS \\
\hline T cells (cells/uL) & $735.76 \pm 459.27$ & $714.13 \pm 291.77$ & $755.00 \pm 577.50$ & NS \\
\hline B cells (\%) & $10.79 \pm 6.05$ & $10.88 \pm 6.73$ & $10.72 \pm 5.58$ & NS \\
\hline B cells (cells/uL) & $111.71 \pm 99.54$ & $105.69 \pm 95.79$ & $117.06 \pm 105.23$ & NS \\
\hline T cells CD4+ (\%) & $48.26 \pm 13.29$ & $49.75 \pm 12.01$ & $46.94 \pm 14.54$ & NS \\
\hline T cells CD4+ (cells/uL) & $505.35 \pm 404.79$ & $504.75 \pm 334.32$ & $505.84 \pm 468.45$ & NS \\
\hline T cells CD8+ (\%) & $23.82 \pm 13.06$ & $24.50 \pm 10.97$ & $23.22 \pm 14.97$ & NS \\
\hline T cells CD8+ (cells/uL) & $209.85 \pm 134.00$ & $218.94 \pm 118.10$ & $201.78 \pm 149.68$ & NS \\
\hline
\end{tabular}


Table 2 Laboratory Results (Continued)

\begin{tabular}{lllll}
\hline & $\begin{array}{l}\text { Total } \\
(\boldsymbol{n}=\mathbf{8 1})\end{array}$ & $\begin{array}{l}\text { Age 65-79 } \\
(\boldsymbol{n}=\mathbf{4 1})\end{array}$ & $\begin{array}{l}\text { Age } \geq \mathbf{8 0} \\
(\boldsymbol{n}=\mathbf{4 0})\end{array}$ & $\boldsymbol{p}$ value \\
\hline NK cells (\%) & $14.25 \pm 10.79$ & $12.44 \pm 7.72$ & $15.83 \pm 12.95$ \\
NK cells (cells/uL) & $129.06 \pm 98.44$ & $111.19 \pm 74.55$ & $144.94 \pm 115.49$ \\
CD4+/CD8+ & $2.81 \pm 1.67$ & $2.60 \pm 1.36$ & $3.01 \pm 1.92$ & $\mathrm{NS}$ \\
\hline
\end{tabular}

Was used Bonferroni correction for multiple comparisons. The statistical adjusted significance was accepted at the adjusted $p$ value $<0.0008$

Abbreviations: $W B C$ white blood cells, $M$ thousand, $N L R$ neutrophil to lymphocyte ratio, $P L R$ platelet to lymphocyte ratio, $N K$ natural killer

\section{Discussion}

Elderly are generally defined as having a chronological age of 65 years or older [18]. In Japan, where many elderly people live, this definition was reviewed [19]. Thanks to the advances in medical and health science the lifespan has recently increased in Japan as well as in Italy. The simple chronological age appears to be no longer appropriate to the actual situation, in both Countries, where life expectancy is of 80 years and where there is an increased number of bright and energetic elderly people. Therefore, in Japan, the term of "late elderly" was introduced to indicate a new class of people, older than 75 years of age [18]. Other factors besides the chronological age appear to play a major role in affecting the health status and the expectance of life and a careful assessment of the "elderly frailty" is required to determine the biological, functional, cognitive and clinical aspects of the elderly subjects [20]. Previous reports indicate that elderly people are particularly susceptible to Community-Acquired Pneumonia [21-23]. When a community-acquired pneumonia is diagnosed in very elderly people, there is a significant increase in morbidity and mortality [24]. It has been observed that these patients often develop hospital-acquired complications and mortality occurs more frequently compared to younger people and to elderly ones. Moreover, the occurrence of pneumonia in elderly people is often the terminal event that complicates a long-term illness, such as dementia, cardiovascular disease, cancer, or prolonged immobilization syndrome [25]. However, it is not always easy to dissect the relative contribution of other factors, including disability, frailty, comorbidities and the health status of these patients, prior to the development of the disease. COVID-19 is a severe disease, caused by the SARS-CoV-2 virus, mostly affecting the lung where an interstitial viral pneumonia is frequently observed, with typical patchy bilateral ground glass opacities and peripheral consolidations. Elderly people appear to be more susceptible, especially to the more severe forms of the disease [26]. However, little information is available so far regarding the course of COVID 19 in very elderly people. It is well established that COVID19 occurs more frequently among elderly people, with higher susceptibility to mortality and ICU admission [27], but a limited number of studies and of patients has focused the attention on a population over eighty years of age [3].

Our very elderly patients, showed a more severe disease, with higher level of serum marker of inflammation (hs-CRP and NLR) and higher severity respiratory indexes (PSI and P/F). This could be due to the increased inflammatory activity, associated with aging, reflected by increased circulating levels of TNF-alpha, IL-6, cytokine antagonists and acute phase proteins in vivo [28].

Experimental observations in mice, indicate that the SARS-CoV viral replication in aged mice is associated with clinical illness and pneumonia, demonstrating an age-related susceptibility to SARS disease in animals that parallels the human experience [29]. Moreover, they demonstrated that replication of SARS CoV is enhanced

Table 3 CT findings

\begin{tabular}{|c|c|c|c|c|}
\hline & $\begin{array}{l}\text { Total } \\
(n=81)\end{array}$ & $\begin{array}{l}\text { Age 65-79 } \\
(n=41)\end{array}$ & $\begin{array}{l}\text { Age } \geq 80 \\
(n=40)\end{array}$ & $\overline{p \text { value }}$ \\
\hline Monolateral (n, \%) & $13(16.04 \%)$ & $6(14.6 \%)$ & $7(17.5 \%)$ & NS \\
\hline Bilateral (n, \%) & 67 (82.71\%) & $34(82.9 \%)$ & $33(82.5 \%)$ & NS \\
\hline Single Lobe lesion (n, \%) & $13(16.04 \%)$ & $6(14.6 \%)$ & $7(17.5 \%)$ & NS \\
\hline Multiple Lobe lesion (n, \%) & 67 (82.71\%) & 34 (82.9\%) & $33(82.5 \%)$ & NS \\
\hline GGO $(n, \%)$ & $66(81.48 \%)$ & $34(82.9 \%)$ & $32(80 \%)$ & NS \\
\hline Consolidations (n, \%) & $53(65.4 \%)$ & $25(60.9 \%)$ & $28(70 \%)$ & NS \\
\hline Pleural effusion (n, \%) & $31(38.3 \%)$ & $11(26.8 \%)$ & $20(50 \%)$ & 0.03 \\
\hline
\end{tabular}

Was used Bonferroni correction for multiple comparisons. The statistical adjusted significance was accepted at the adjusted $p$ value $<0.0008$ 


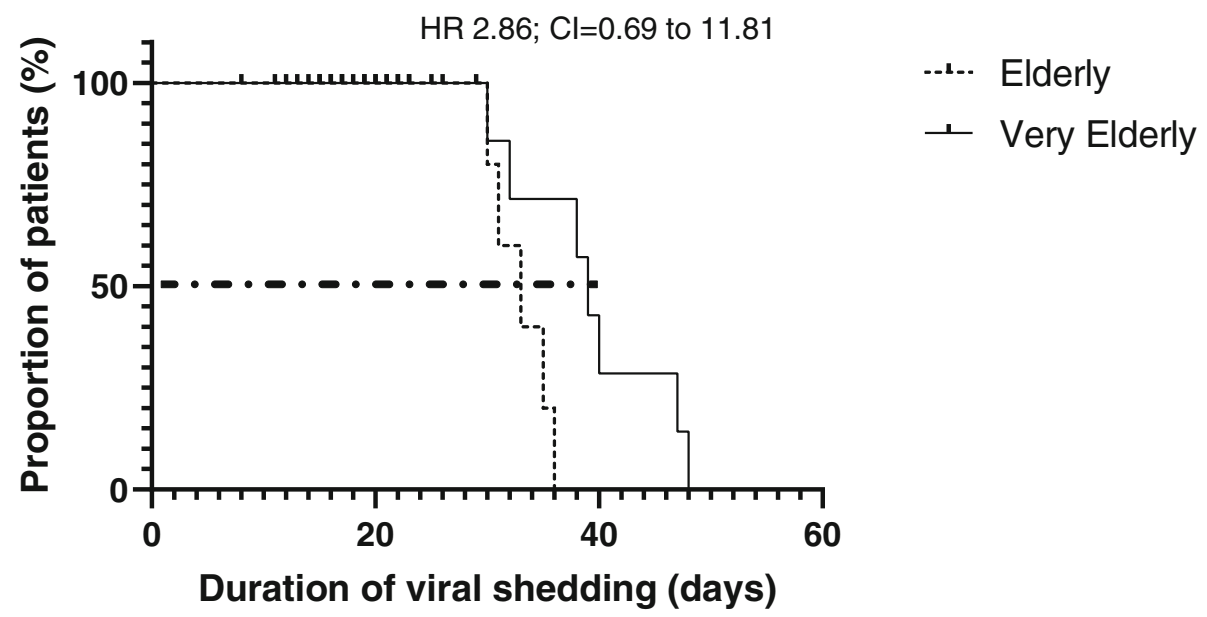

Fig. 1 Kaplan-Meier curves representing the proportion of patients with detectable Viral RNA after 30 days from the onset of symptoms. (HR 2.86; $95 \%$ Cl 0.69-11.81; $p$ value $=0.03$ )

in aged mice compared to younger and enhanced viral replication is accompanied by evidence of clinical illness, alveolar damage, and interstitial pneumonitis [29].

Besides to be stroked by a more severe disease, median duration of viral shedding in our very elderly patients is higher compared to that recently reported in younger and symptomatic (14 days) or asymptomatic patients (19 days) [30] and there is a statistically significant difference between the two groups. This also affects the length of the stay (LOS) in the hospital which result higher in Very Elderly. We don't have data regarding the immune response in terms of cytokine production and production of specific immunoglobulins in our very elderly patients. However, the increased duration of viral shedding suggests that they may have a weaker immune response to SARS-CoV-2 infection, compared to younger patients. Increasing age has been defined as a predictive factor for mortality in pneumonia patients in many studies, especially among patients aged 65 years or older [31, 32]. Several studies, suggested that age $\geq 85$ years was an independent predictive factor for mortality in patients affected with community acquired pneumonia $[33,34]$. Calle et al. reported that age $\geq 90$ years was markedly associated with mortality [35]. Ageing is associated with a progressively weakened immune system and decreased lung performance. For patients of extreme age ( $\geq 85$ years in our study), these changes alone are probably drastic, which independently increases the risk of death due to pneumonia [34]. In the study by Zunyou $\mathrm{Wu}$ et al., the overall case-fatality rate of those aged 70

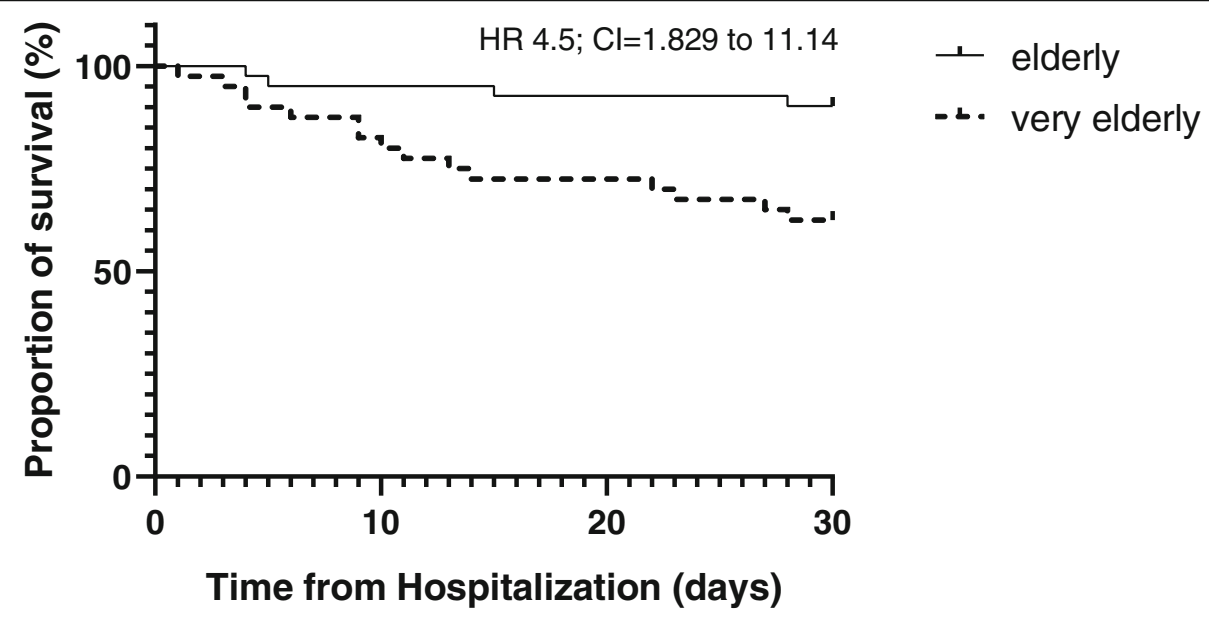

Fig. 2 Kaplan-Meier survival curve for COVID 19 stratified by age. (HR 4.5; 95\% Cl 1.8-11.14; $p$ value =0.003) 
Table 4 Univariate Analysis

\begin{tabular}{llll}
\hline Variables & \multicolumn{3}{l}{ Univariate } \\
\cline { 2 - 4 } & OR & $\mathbf{9 5 \% C l}$ & $\boldsymbol{p}$ value \\
\hline Age & 1.109 & 1.031 to 1.206 & 0.004 \\
Comorbidities & 1.69 & 1.124 to 2.652 & 0.01 \\
LSRCHs & 3.29 & 1.057 to 12.58 & 0.03 \\
\hline
\end{tabular}

Abbreviations: $O R$ odds ratio, $\mathrm{Cl}$ confidence interval

to 79 years was $8.0 \%$ compared to aged 80 years and older where it was $14.8 \%$ [36]. However, in this study only $3 \%$ of the total number of cases were 80 years of age or older. In another study by Niu et al., the mortality rate in patients over 80 was equal to $18 \%$ [3]. Also Yan et al. reported that older patients ( $>65$ years) with comorbidities and ARDS are at increased risk of death, although even in this study patients over 80 years of age were a small number [37].

In our study the number of patients with more than 80 years of age is similar to that with $65-79$. The mortality rate in Very Elderly was $37.5 \%$ and this percentage was significantly higher compared to that observed in Elderly. Our findings suggest that, similarly with other severe acute respiratory outbreaks, age is a fundamental risk factor for mortality. These results also emphasize the importance of the very advanced age (i.e. $\geq 85$ years).

When we try to identify which factors other than age may influence the course and outcome of the disease in these patients, two conditions appear to play a major role. The first is represented by the pre-existing health conditions or comorbidities. Patients with pre-existing pathological diseases, and in particular those affected by multiple comorbidities die more frequently than those with no or few comorbidities. In other words, COVID19 , as other community-acquired pneumonias, acts as terminal event that complicates long-term illnesses. This is in agreement with previous studies demonstrating that the presence of any comorbidity is associated with increased risk of poorer clinical outcomes [38].

The second one consisted in the observation that patients admitted to the hospital coming from previous LSRCHs, were in worst clinical conditions and died more frequently compared to those admitted coming from their homes. There are many possible explanations to that. Patients in LSRCHs may suffer of more

Table 5 Multivariate Analysis

\begin{tabular}{llllll}
\hline Variables & \multicolumn{2}{l}{ Multivariate Model $\mathbf{1}$} & & \multicolumn{2}{c}{ Multivariate Model 2 } \\
\cline { 2 - 3 } & OR & $\mathbf{9 5 \% C l}$ & & OR & $\mathbf{9 5 \% C l}$ \\
\hline Age & 1.099 & 1.013 to 1.209 & & 1.109 & 1.031 to 1.206 \\
Comorbidities & 1.732 & 1.084 to 2.864 & & \\
LSRCHs & 2.168 & 0.599 to 9.088 & & \\
\hline
\end{tabular}

Hosmer and Lemeshow goodness-of-fit test, $p=0.79$

Abbreviations: $\mathrm{OR}$ odds ratio, $\mathrm{Cl}$ confidence interval comorbidities and fragilities, and as previously observed they are more prone to accumulate complications, thus resulting in unfavorable outcome. Another explanation is that, staying in a close environment, makes these patients more susceptible to infections. In this regard, the results of the Italian National Survey indicated that one of the major difficulties was to obtain an adequate isolation of the positive patients. Finally, the disease could be more severe because of a delay in its recognition, that, according to this survey, was due to insufficient availability of the nasal/oropharyngeal tests. Considering all these factors and based on our observations, it is necessary to obtain a better evaluation of the frailties of elderly and very elderly people that represent a population more prone to the condition of risk and vulnerability, characterized by an unstable equilibrium, if facing negative events.

Because of the rapid evolving outbreak globally, ongoing studies with the inclusion of more patients would be needed to increase the statistical power of our results.

\section{Conclusions}

In conclusion, the heightened susceptibility of the elderly to COVID 19, led us to demonstrate that there were considerable differences between Elderly and Very Elderly in terms of inflammatory activity, severity of disease and adverse clinical outcomes. Although age is one of the major risk factors for mortality, a thorough assessment of comorbidities and information about the provenience from residential care homes may help establishing risk stratification of patients with COVID-19 upon hospital admission and may furnish valuable information for planning adequate programs of intervention at the sanitary-assistential levels.

\section{Abbreviation}

LSRCHs: Long-stay residential care homes

\section{Acknowledgements}

We are deeply grateful to the COVID-19 Sant'Andrea Group and in particular to Prof. Luciano De Biase, Prof. Paolo Martelletti, Prof. Antonio Aceti and to Prof. Monica Rocco for their support in the presentation of the study for the approval by our Institutional Review Board. We thank also the hospital staff (S. Giovagnoli, G. Gencarelli, A. Moretta, F. Ravà, A. Carraturo, M. Chianese, C. Salvucci, A. Pagliuca, R. Sglavo, F. Scarso, P. Bruno, M. Aquilini, T. Sordi) for the clinical management or our COVID-19 patients.

\section{Authors' contributions}

This study was designed, directed and coordinated by M.D., M.I., L.P., D.P., S.C., contributed to acquisition, analysis and interpretation of data. G.G., A.P., C.D.V., R.M., A.M., P.A., A.R., S.S., contributed to writing, the revision and the submission of the article. All authors read and approved the final manuscript.

\section{Funding \\ Not received.}

\section{Availability of data and materials}

The data that support the plots within this paper and other finding of this study are available from the corresponding author upon reasonable request. 


\section{Ethics approval and consent to participate}

The study was approved by our Institutional Ethical Committee (Sapienza University of Rome, Italy) (Prot.\# 52SA_2020, RIF. CE 5773_2020), on the basis that it complied with the declaration of Helsinki and that the protocol followed existing good clinical practice guidelines. A written informed consent to participate in the study was obtained from every participant. In case of adults with cognitive decline the consent to participate to the study was given by the legal guardian. An administrative permission to access the clinical/personal patient data used in our research was given by the Health Director of our Hospital, who is also a co-author of the manuscript.

\section{Consent for publication}

Not applicable.

\section{Competing interests}

The authors declare they have no conflict of interest.

\section{Author details}

'Division of Pneumology, Sant'Andrea Hospital, Via di Grottarossa, 1035-1039, 00189 Rome, Italy. ${ }^{2}$ Department of Clinical and Molecular Medicine, Sapienza University, Viale Regina Elena n. 324, 00161 Rome, Italy. ${ }^{3}$ Health Director, Sant'Andrea Hospital, Via di Grottarossa, 1035-1039, 00189 Rome, Italy. ${ }^{4}$ General Director, Sant'Andrea Hospital, Via di Grottarossa, 1035-1039, 00189 Rome, Italy. ${ }^{5}$ Laboratory of Biomedical research, Niccolò Cusano University Foundation, Via Don Carlo Gnocchi, 3, 00166 Rome, Italy.

Received: 16 July 2020 Accepted: 6 January 2021 Published online: 15 January 2021

\section{References}

1. Salute M della. Covid-19 - Situazione in Italia. Accessed June 20, 2020. http://www.salute.gov.it/portale/nuovocoronavirus/ dettaglioContenutiNuovoCoronavirus.jsp?lingua=italiano\&id=5351\&area= nuovoCoronavirus\&menu=vuoto

2. Liu K, Chen Y, Lin R, Han K. Clinical features of COVID-19 in elderly patients: a comparison with young and middle-aged patients. J Inf Secur. 2020;80(6): e14-8. https://doi.org/10.1016/j.jinf.2020.03.005.

3. Niu S, Tian S, Lou J, et al. Clinical characteristics of older patients infected with COVID-19: a descriptive study. Arch Gerontol Geriatr. 2020;89:104058. https://doi.org/10.1016/j.archger.2020.104058.

4. Monasta L, Abbafati C, Logroscino G, et al. Italy's health performance, 19902017: findings from the global burden of disease study 2017. Lancet Public Health. 2019;4(12):e645-57. https://doi.org/10.1016/S2468-2667(19)30189-6.

5. Mortality associated with COVID-19 outbreaks in care homes: early international evidence. Resources to support community and institutional Long-Term Care responses to COVID-19. Published April 12, 2020. Accessed June 29, 2020. https://tccovid.org/2020/04/12/mortality-associated-withcovid-19-outbreaks-in-care-homes-early-international-evidence/

6. OECD, European Union. Health at a Glance: Europe 2020: State of health in the EU cycle, vol. 2020: OECD. https://doi.org/10.1787/82129230-en.

7. sars-cov-2-survey-rsa-rapporto-finale.pdf. Accessed June 29, 2020. https:// www.epicentro.iss.it/coronavirus/pdf/sars-cov-2-survey-rsa-rapporto-finale. pdf

8. 4b14b829-5a07-24e9-955a-4d4c9a7e4440.pdf. Accessed November 14, 2020 https://www.iss.it/documents/20126/0/Report_surveyFinale+RSA.pdf/4b14 b829-5a07-24e9-955a-4d4c9a7e4440?t=1592402115720

9. Swann OV, Holden KA, Turtle $L$, et al. Clinical characteristics of children and young people admitted to hospital with covid-19 in United Kingdom: prospective multicentre observational cohort study. BMJ. 2020;370. https:// doi.org/10.1136/bmj.m3249.

10. Knopp P, Miles A, Webb TE, et al. Presenting features of COVID-19 in older people: relationships with frailty, inflammation and mortality. Eur Geriatr Med. Published online July 30. 2020:1-6. https://doi.org/10.1007/s41999-02000373-4.

11. Petretto DR, Pili R. Ageing and COVID-19: What is the Role for Elderly People? Geriatrics (Basel). 2020;5(2). https://doi.org/10.3390/ geriatrics5020025.

12. Italy Demographics 2020 (Population, Age, Sex, Trends) - Worldometer. Accessed June 20, 2020. https://www.worldometers.info/demographics/ italy-demographics/
13. Chen N, Zhou M, Dong X, et al. Epidemiological and clinical characteristics of 99 cases of 2019 novel coronavirus pneumonia in Wuhan, China: a descriptive study. Lancet. 2020;395(10223):507-13. https://doi.org/10.1016/ s0140-6736(20)30211-7.

14. Zhou S, Wang Y, Zhu T, Xia L. CT features of coronavirus disease 2019 (COVID-19) pneumonia in 62 patients in Wuhan, China. Am J Roentgenol. 2020;214(6):1287-94. https://doi.org/10.2214/AJR.20.22975.

15. Caruso D, Zerunian M, Polici M, et al. Chest CT Features of COVID-19 in Rome, Italy. Radiology. Published online April 3. 2020:201237. https://doi. org/10.1148/radiol.2020201237.

16. Zhou F, Yu T, Du R, et al. Clinical course and risk factors for mortality of adult inpatients with COVID-19 in Wuhan, China: a retrospective cohort study. Lancet. 2020;395(10229):1054-62. https://doi.org/10.1016/S01406736(20)30566-3.

17. Qi L, Yang $Y$, Jiang $D$, et al. Factors associated with the duration of viral shedding in adults with COVID-19 outside of Wuhan, China: a retrospective cohort study. Int J Infect Dis. 2020;96:531-7. https://doi.org/10.1016/j.ijid. 2020.05.045

18. Ouchi $Y$, Rakugi $H$, Arai $H$, et al. Redefining the elderly as aged 75 years and older: proposal from the joint Committee of Japan Gerontological Society and the Japan geriatrics society. Geriatr Gerontol Int. 2017;17(7):1045-7. https://doi.org/10.1111/ggi.13118.

19. Orimo H, Ito H, Suzuki T, Araki A, Hosoi T, Sawabe M. Reviewing the definition of "elderly." Geriatr Gerontol Int 2006;6(3):149-158. doi:https://doi. org/10.1111/j.1447-0594.2006.00341.x.

20. Malaguarnera M, Vacante M, Frazzetto PM, Motta M. What is the frailty in elderly? Value and significance of the multidimensional assessments. Arch Gerontol Geriatr. 2013;56(1):23-6. https://doi.org/10.1016/j.archger.2011.09. 017.

21. Cunha BA. Pneumonia in the elderly. Clin Microbiol Infect. 2001;7(11):581-8. https://doi.org/10.1046/j.1198-743x.2001.00328.x.

22. Marrie TJ. Community-acquired pneumonia in the elderly. Clin Infect Dis. 2000;31(4):1066-78. https://doi.org/10.1086/318124.

23. Torres A, El-Ebiary M, Riquelme R, Ruiz M, Celis R. Community-acquired pneumonia in the elderly. Semin Respir Infect. 1999;14(2):173-83.

24. Fernández-Sabé N, Carratalà J, Rosón B, et al. Community-acquired pneumonia in very elderly patients: causative organisms, clinical characteristics, and outcomes. Medicine (Baltimore). 2003;82(3):159-69. https://doi.org/10.1097/01.md.0000076005.64510.87.

25. Corrales-Medina VF, Alvarez KN, Weissfeld LA, et al. Association between hospitalization for pneumonia and subsequent risk of cardiovascular disease. JAMA. 2015;313(3):264-74. https://doi.org/10.1001/jama.2014. 18229.

26. Xue Q-L. Frailty as an integrative marker of physiological vulnerability in the era of COVID-19. BMC Med. 2020;18(1):333. https://doi.org/10.1186/s12916020-01809-1.

27. CDC COVID-19 Response Team. Severe Outcomes Among Patients with Coronavirus Disease 2019 (COVID-19) - United States, February 12-March 16, 2020. MMWR Morb Mortal Wkly Rep. 2020;69(12):343-6. https://doi.org/10. 15585/mmwr.mm6912e2.

28. Bruunsgaard $H$, Pedersen $M$, Pedersen BK. Aging and proinflammatory cytokines. Curr Opin Hematol. 2001;8(3):131-6. https://doi.org/10.1097/ 00062752-200105000-00001.

29. Roberts A, Paddock C, Vogel L, Butler E, Zaki S, Subbarao K. Aged BALB/C mice as a model for increased severity of severe acute respiratory syndrome in elderly humans. J Virol. 2005;79(9):5833-8. https://doi.org/10.1128/JVI.79.9. 5833-5838.2005.

30. Long Q-X, Tang X-J, Shi Q-L, et al. Clinical and immunological assessment of asymptomatic SARS-CoV-2 infections. Nat Med Published online June 18. 2020:1-5. https://doi.org/10.1038/s41591-020-0965-6.

31. Sligl WI, Eurich DT, Marrie TJ, Majumdar SR. Age still matters: prognosticating short- and long-term mortality for critically ill patients with pneumonia. Crit Care Med. 2010;38(11):2126-32. https://doi.org/10.1097/ CCM.0b013e3181eedaeb.

32. Fine MJ, Auble TE, Yealy DM, et al. A prediction rule to identify low-risk patients with community-acquired pneumonia. N Engl J Med. 1997;336(4): 243-50. https://doi.org/10.1056/NEJM199701233360402.

33. Conte HA, Chen Y-T, Mehal W, Phil D, Scinto JD, Quagliarello VJ. A prognostic rule for elderly patients admitted with community-acquired pneumonia. Am J Med. 1999;106(1):20-8. https://doi.org/10.1016/S00029343(98)00369-6. 
34. Zhang ZX, Yong $Y$, Tan WC, Shen L, Ng HS, Fong KY. Prognostic factors for mortality due to pneumonia among adults from different age groups in Singapore and mortality predictions based on PSI and CURB-65. Singap Med J. 2018;59(4):190-8. https://doi.org/10.11622/smedj.2017079.

35. Calle A, Márquez MA, Arellano M, Pérez LM, Pi-Figueras M, Miralles R. Geriatric assessment and prognostic factors of mortality in very elderly patients with community-acquired pneumonia. Arch Bronconeumol. 2014; 50(10):429-34. https://doi.org/10.1016/j.arbres.2014.01.012.

36. Wu Z, McGoogan JM. Characteristics of and important lessons from the coronavirus disease 2019 (COVID-19) outbreak in China: summary of a report of 72314 cases from the Chinese Center for Disease Control and Prevention. JAMA. 2020;323(13):1239-42. https://doi.org/10.1001/jama.2020 2648.

37. Yang $X, Y u, Y, X u$ J, et al. Clinical course and outcomes of critically ill patients with SARS-CoV-2 pneumonia in Wuhan, China: a single-centered, retrospective, observational study. Lancet Respir Med. 2020;8(5):475-81. https://doi.org/10.1016/S2213-2600(20)30079-5.

38. Guan W-J, Liang W-H, Zhao Y, et al. Comorbidity and its impact on 1590 patients with COVID-19 in China: a nationwide analysis. Eur Respir J. 2020; 55(5). https://doi.org/10.1183/13993003.00547-2020.

\section{Publisher's Note}

Springer Nature remains neutral with regard to jurisdictional claims in published maps and institutional affiliations.

Ready to submit your research? Choose BMC and benefit from:

- fast, convenient online submission

- thorough peer review by experienced researchers in your field

- rapid publication on acceptance

- support for research data, including large and complex data types

- gold Open Access which fosters wider collaboration and increased citations

- maximum visibility for your research: over $100 \mathrm{M}$ website views per year

At BMC, research is always in progress.

Learn more biomedcentral.com/submissions 